\title{
Retinitis pigmentosa and adjustment disorder in a clinical
}

\section{case}

\author{
Christina Jane Gangos and Athena Stefanatou* \\ School of Graduate and Professional Education, Psychology Department, Deree-The American College of Greece, Greece
}

\section{Background information}

Miss B.B. is a 30 -year-old American-born female, who moved to Athens/ Greece in March 2017. She has never been married and has no children. Her parents are divorced and both alive in their mid-60's. She has one twin sister who lives alone in the United States. She studied her bachelor's and Master of Fine Art in English literature with an emphasis on poetry at an Ivy League university. She became an assistant professor in creative writing from 2010-2015 in two prestigious universities in the United States and at the same time volunteered to teach literacy in underprivileged community centers in her area. Before moving to Greece, she had a 10-year relationship with a medical doctor who she was living with. At that time, she also had a rich social life, describing many friendships and acquaintances. She drinks socially but not a regular basis and does not engage in drug use.

\section{Medical history, diagnosis, progression and adjustment}

$\mathrm{BB}$ was first diagnosed with retinitis pigmentosa at the age of 5 when she began to have a hard time reading the blackboard in her kindergarten. She was given glasses and lived as a fully sighted person throughout her teenage years, even obtaining a driver's license at the age of 16 . When she entered college she slowly started to experience more significant sight loss, eventually being unable to read even with magnification. She was unable to see in the dark (nyctalopia) and had lost more of her peripheral vision [1]. She began to fear walking in unfamiliar settings at night without someone accompanying her. At this time, she decided to turn in her driver's license and began training to use a cane. When she finished college, she applied for her first guide dog but was still able to walk during the day without the dog when in familiar environments. At 25, she began to rely more and more on her cane and/or guide dog and stopped reading regular text completely, needing a computerized zoom and "text to speech" to access textual material. At around the age of 28, she recalls experienced another dip in her visual acuity which she described as "considerable".

\section{Family and personal history}

$\mathrm{BB}$ has a very close relationship with her sister who she describes as "fiercely affirmative, resilient, supportive, and brave". BB says that in her most difficult moments "my sister helped me practically, emotionally, and psychologically cope by essentially facing similar challenges first and under worse circumstances". Further to this BB described having a good relationship with her father who lives with his second wife in the United States. She says that her father has been "unconditionally affirmative and supportive, but not vocally or practically so". Finally, she does not have any relations with her mother who has "cut ties" with both her daughters as she could not cope with many aspects of both her children's disorder. BB told me that her mother struggles with a mental disorder but was not open to saying what the exact psychiatric diagnosis is. Furthermore, BB has many friends and is generally socially extroverted, often relying on and asking for practical help from her social relationships. She is not currently in a romantic relationship.

\section{Life difficulties}

BB describes several life difficulties in her early childhood years, which specifically connect to her mother. She says her mother, who is deeply religious, would hover between believing her children's disorder was a "curse from God" or that it does not existent. She described her mother as a "neglectful caregiver" experiencing mood swings that would impact the way she related to her children. She would often shout and scream, and other times fall into "very sad" phases.

Another important difficulty faced by the client was her strained relationship to her former partner of 10 years. Her former partner, a medical doctor is described as psychologically abusive and controlling, often threatening to leave her "for no clear reason". BB describes that he would not allow her to walk with her guide dog whilst with him and would force her to hold his hand. The client also says that her expartner did not want to have children with her because of her condition. An event that further exacerbated her psychological state was in 2009 when her partner who she has had become dependent on, moved away to another state to begin his medical degree, which led her to feel very depressed and anxious. She felt exhausted having to establish a more independent routine whilst also experiencing a sense of abandonment.

\section{Coping skills and weaknesses}

$\mathrm{BB}$ believes she is a very sensitive and perceptive person who is not afraid to ask for the help from others or give help in return. She is not afraid of being challenged and takes life as it comes. BB says she has the tendency to use the difficult moments to become stronger and more resilient and "does not wallow self-pity".

BB believes that her weaknesses relate to her often liming herself and what she thinks she can achieve in the future based on her eye disorder. She also says that she easily stresses and thinks bad thoughts about little things.

Correspondence to: A Stefanatou, Graduate School, Deree The American College of Greece, 6 Gravias Str. Athens 15342, Greece, E-mail: astefanatou@acg.edu

Received: February 07, 2018; Accepted: February 21, 2018; Published: February 26, 2018 


\section{Presenting problem}

\section{Current physical state}

$\mathrm{BB}$, at the age of 30 presented with the physical symptomology of retinitis pigmentosa and specifically Enhanced S-cone Syndrome (Goldman-Favre syndrome) [2]. Her condition has taken the expected course with the almost complete loss of peripheral vision, an increased sensitivity to blue light, night blindness and a very narrow field of vision ("tunnel vision") with only a few degrees in the very center that can detect light. She describes her vision as "looking through a pinhole and seeing just a little bit at a time". When describing that small field of vision, she says it is "blurry vision but fairly functional; I see colors and shapes well". She describes not generally being able to distinguish facial features without exhausting physical effort which narrows her field of vision even further. About this she says, "It's sort of like when you are a kid and walk around with an empty paper towel tube".

Her doctor has told her that the condition is not treatable. Over the course of her condition, she has seen many specialists who have suggested different strategies that could potentially help her maintain some vision for longer. These have namely been: avoiding stress, maintain a healthy diet, avoiding psycho-stimulants and being careful about the overuse of remaining vision. What she has personally found helpful has been practicing yoga on a daily basis, getting adequate amounts of sleep and rest, a regular and healthy diet, and some sessions of acupuncture two or three times a year. What she has found makes the condition worse is exposure to fluorescent lights, flashing and bright lights, loud noises, and overcrowded spaces with moving obstacles that disorientate her.

Since moving to Athens $\mathrm{BB}$ has fallen on the street twice, resulting in excessive facial and corporal bruising. Since then she has been extra cautious as it is almost impossible to know what is around her due to her ring scotoma. She did not visit the doctor after the falls even though her friends and acquaintances were shocked by her appearance.

\section{Current psychological state}

$\mathrm{BB}$ was referred for psychological treatment due to feeling "anxious and stressed" ever since she arrived in Athens, Greece from the United States, three months ago. Her anxiety is characterized by excessive worrying, jitteriness, especially at night hours, oversensitivity to noise, as well as thinking about her family back home often. She is sometimes tearful and has a hard time consoling herself. She does not want to go out when the sun goes down as she has a harder time navigating the unfamiliar Athens terrain as she generally has almost no vision when the light is gone. She is also concerned about her dog who she feels is also very stressed and "different" in this transition. $M$, the dog is her only means of getting around which she sometimes combines with a cane.

BB says she came to Greece to be with a man she met in the USA who lives in an affluent Athens suburb. However, her expectations for this relationship were not met and the relationship has since ended. Nevertheless, BB has the desire to stay in Athens and travel Greece as she finds it an inspiring place for her poetry. The psychological symptoms described have been present for the last three weeks.

BB believed that life in Athens will be harder than what she anticipated but she feels it is very important that she gets through this time. She believes that her symptoms, which she has experienced before, are due to the new environment, the higher noise levels and the fact that the dog is "not being herself".

\section{Views on condition}

When I asked BB, how she views her current eye condition she said that she knows that her condition is "slow progressing and untreatable". She continued by saying that she believes her condition has made her stronger and a more sensitive person. Further to this, she also believes the condition is inconvenient and at times dangerous "but more often than not it is a delicate complication or enabling constraint". After a long pause, she continued by saying "I guess I will lose all perception of light at some point, but I don't think about it, specifically".

When describing her mother's views of the condition, BB says that her mother believed it is a "curse from God". She remembers her mother praying every night for a cure. Often her mother would act as if both her daughters did not have a visual condition. When describing an incident, she says, after one of the first days her sister had been working with a guide dog, she gave her an "I Spy" book as a gift which was meant for an older child. Over time, if she acknowledged it at all, she responded in "usual ways" according to BB. The patient described an incident, where her mother, who suffered from arthritis in her wrists would say that she was "more disabled than her daughters".

BB says that the hardest part about her condition has been other people's reactions to it. The first time she sought counseling, 5 years ago, was because of the reaction of her ex-partner who she says was very unsupportive and sometimes abusive toward her. He would often not allow her to use a cane or dog when walking in the street with him and demanded he cold his arm instead. BB also described her expartner not wanting to commit to her or have children with her due to the fact that as a medical doctor he knew how bad her eye condition would get. She became very distressed due to these views and sought counseling once before because of this.

When describing the reactions of her friends in college she says that they were varied but generally she often was met with comments such as 'fascinating!', 'I'm so sorry...' 'wait, really?'. Strangers often expressed disbelief and doubt about her being blind "Are you really blind?" "You're not actually blind, right?". BB says that in late college when living with roommates and consistently using their toothbrush accidentally, her friends confronted her with the fact that her eyesight was getting worse.

\section{Screening and diagnostic assessments}

Visual conditions are highly associated with depression and poor quality of life [3], and hence it was important to assess the client both for depression and quality of life due to visual disability

The client was given the Beck Depression Inventory which is a 21- item, self-report rating inventory used to identify and assess symptomatology and is considered to be highly reliable in diverse populations.

National Eye Institute Visual Functioning Questionnaire - 25 which assesses problems relating to visual condition and feelings about visual condition [4]. Only 11 out of 25 questions were used from the second assessment as all other questions were deemed as inappropriate to the specific client. The assessment measure was used to assess the client current state both physical and psychological. The following questions were used: How much of the time do you worry about your eyesight? 2. How much difficulty do you have reading street signs or the names of stores? 3. Because of your eyesight, how much difficulty do you have going down steps, stairs, or curbs in dim light or at night? 4. Because of your eyesight, how much difficulty do you have noticing objects off to 
the side while you are walking along?5. Because of your eyesight, how much difficulty do you have seeing how people react to things you say? 6. Because of your eyesight, how much difficulty do you have visiting with people in their homes, at parties, or in restaurants ?7. Because of your eyesight, how much difficulty do you have going out to see movies, plays, or sports events? 8. Do you accomplish less than you would like because of your vision?9. I stay home most of the time because of my eyesight I feel frustrated a lot of the time because of my eyesight 10. I have much less control over what I do, because of my eyesight. 11. I need a lot of help from others because of my eyesight.

The raw score for the BDI was 13 indicated minimal depression. The information from the selected questions highlighted the dependency the client has on others, maybe giving a clue on why she has started experiencing excessive anxiety in this new environment. It also highlighted that the client has problems with both near activity and distant activity.

\section{DSM diagnosis}

BB's symptomatology is best described by an Adjustment disorder diagnosis with an anxiety specifier 309.24 (F43.22) [5].

A. BB's symptoms development, both emotional and behavioral, have occurred in the last three weeks and do not constitute an ongoing situation

B. Their symptoms or behaviors are clinically significant, as evidenced by:

1. She experiences marked distress that is out of proportion to the stressor

2. she experiences impairment in her day to day functioning, not leaving the house at night and having a hard time getting a job.

C. the stress related disturbance does not meet the criteria for another mental disorder and is not merely an exacerbation of a preexisting mental disorder as the client does not have a previous diagnosis.

\section{The symptoms do not represent normal bereavement.}

E. Once the stressor is terminated we can assume that the symptoms are alleviated.

The diagnosis of adjustment disorder was given because symptomatology does not qualify for a depression diagnosis but is not symptom free either [6]. BB does not describe persistent feelings of sadness but rather a feeling that sadness and tearfulness comes and goes. BB describes still taking pleasure in activities she used to when living in the USA but also expresses having a harder time getting access to such activities. She has not changed in weight and has a good appetite. She does experience sleeping for longer periods of time however, she spends a large part of the day active. She does not have any sense of worthlessness that she can identify.

\section{Bereavement process}

Another important psychological aspect of BB's experience both in the past and currently may be the aspect of bereavement. Distinctly, when describing the family's and her own views on her condition she also perhaps describing the process of bereavement [7]. Although it might not be feasible or required to work on this at this point of BB's life, as she is experiencing a number of stressful situation, it is important to keep it in mind and if possible integrate into the therapeutic modality whilst contemplating where she may be at this point of her life. For example, it may be important to address if the current situation is placing her back into the process of bereavement. When narrating past experiences the client has described a probable phase of denial in which she describes her family not discussing or acknowledging her condition. Further to this, the fact that she does not seem blind further exacerbates the idea that "she does not have to acknowledge her disorder to people", perhaps isolating herself further. She has also described a clear phase of anger in particular to a moment in 2006 where she had to describe herself as a "low vision" or a "legally blind" person and was filled with "anger and deep sadness". She says she had to bridge her life from being a "normal sighted person" and knowing how to do things with her visual field intact to being a "blind person" not knowing how to live comfortably whilst needing more help. When describing her disorder currently, she has a more accepting view of it, however, the new environment she finds herself in may be pushing her back into the bereavement process or may be giving life to experiences she had in her past that remind her of this process [7].

\section{Therapeutic goals}

Our therapeutic goals and treatment plan should link literature that correlates sight loss with anxiety, depression, loneliness and lack of social support as well as the sense of loss individuals with sight loss experience $[1,6,8,9]$.

The primary therapeutic goal is to relieve symptoms and help BB return to a similar level of functioning to before moving to Greece as she described having fairly good functioning before her move. Secondary the therapeutic process can aid B.B. in changing her perception and reaction to stress-inducing situations and stimuli in the new environment. Another important aspect may be to help the client set goals that relate to her time in Greece, creating meaning in the new setting. At the same time, it is vital that the client be actively working toward situations that involve social inclusion in daily life and hence highlighting the importance of exploring those in session and set goals. Finally, it is perhaps important to locate medical specialists for retinitis pigmentosa in Greece for monitoring her condition whilst in Athens.

\section{Evidence-based treatments}

A suitable therapeutic treatment for $\mathrm{BB}$ would be Cognitive behavioral therapy (CBT) (adjusted for visual impairments) focusing primarily on the stressor and the response to the stressor [10]. This form of treatment uses problem-focused actions that are taken to counteract the source of stress (i.e. new environment), and the responses to alter the emotions produced by the event. Another aspect of this treatment is to investigate the expectations the client had before moving to Greece as well as how those may be adjusted to the reality of the new environment. The use of an activity schedule may accentuate the importance of contact with groups and individuals who are also dealing with low vision in the Athenian context. At the same time, it would be important to evaluate beliefs about independence and dependence in the newly found context and whether any past experiences can help in this adjustment (ex. Adjustment to new environments in the past). Aspects of Problem Solving Therapy (PST) a specialized CBT treatment have shown to be effective in low vision groups and can also be used with B.B [11]. Specifically, defining the problems the client is facing, establishing realistic goals whilst brainstorming possible solutions and evaluating pros and cons of each is is of the essence. Implementing decision making guidelines and choosing preferred solutions can be helpful as the client seems to be overwhelmed by the stress and has a hard time making plans. Through the process of implementing the solution in real life, $\mathrm{BB}$ can work together with the therapist to evaluate 
the outcomes, further strengthening the concept that she can ask for help from others and meet her needs.

Finally, as mentioned above it is important to bear (in mind whether the bereavement process has been triggered once again by this new context either by associations with the past or by the sense of "hopelessness and fear" the client is being faced due the "hostile" terrain of Athens, further exacerbating anger or depression [12].

\section{Social support}

The client often talks about how important social support has been to her in the American context and therefore it is important that this is also present in the Greek context. Giving her information and orienting her to Greek support groups specializing in sight loss is of vital importance to her effective integration. Programs such as the center for education and Rehabilitation of the Blind (KEAT), Lighthouse for the Blind, and the PanHellenic Link for the Blind would be good starting points for a proper orientation to Athens. These groups will offer a realistic outlook with both the negative and positives of the new context. Another key component for social support in her new environment would be to assist her in asking for help from friends and neighbors in getting to know her surroundings and in particular the area most proximate to her home. Simple and practical support in getting around at first is also essential for her safety both physical and mental.

Concluding, there seems to be both a social and psychological need to be attended in such cases. The element of leaving in a foreign country enhances the feeling of estrangement and loss. Support must be acknowledged and materialized so to adhere to both dignity values and actual needs of the person.

\section{References}

1. Hahm BJ, Shin YW, Shim EJ, Jeon HJ, Seo JM, et al. (2008) Depression and the visionrelated quality of life in patients with retinitis pigmentosa. Br J Ophthalmol 92: 650-654.

2. Moschos MM (2014) Physiology and Psychology of Vision and Its Disorders: A Review. Med Hypothesis Discov Innov Ophthalmol 3: 83-90. [Crossref]

3. Moschos M, Chatzirallis A, Chatziralli I (2015) Psychological aspects and depression in patients with retinitis pigmentosa. Eur J Ophthalmol 25: 459-462. [Crossref]

4. Mangione CM, Lee PP, Gutierrez PR, Spritzer K, Berry S, et al. (2001) Development of the 25-item National Eye Institute Visual Function Questionnaire. Arch Ophthalmol 119: $1050-1058$.

5. American Psychiatric A, Force DSMT (2013) Diagnostic and statistical manual of mental disorders: DSM-5. from http://dsm.psychiatryonline.org/book.aspx?bookid=556

6. Jacob L, Spiess A, Kostev K (2017) Prevalence of depression, anxiety, adjustmen disorders, and somatoform disorders in patients with age-related macular degeneration in Germany. Ger Med Sci 15: Doc04. [Crossref]

7. De Leo D, Hickey PA, Meneghel G, Cantor CH (1999) Blindness, fear of sight loss, and suicide. Psychosomatics 40: 339-344

8. Banerjee A, Kumar S, Kulhara P, Gupta A (2008) Prevalence of depression and its effect on disability in patients with age- related macular degeneration. Indian J Ophthalmol 56: 469-474.

9. Brody BL, Gamst AC, Williams RA, Smith AR, Lau PW, et al. (2001) Depression, visual acuity, comorbidity, and disability associated with age-related macular degeneration. Ophthalmology 108: 1893-1900.

10. Rovner BW, Casten RJ, Hegel MT, Massof RW, Leiby BE, et al. (2014) Low Vision Depression Prevention Trial in Age-Related Macular Degeneration: A Randomized Clinical Trial. Ophthalmology 121: 2204-2211.

11. Riazi A, Walters K, Rubin G, Ambler G, Jichi F, et al. (2014) A pilot randomised controlled trial of Problem-Solving Treatment for Visual Impairment (POSITIVE): protocol paper. Ophthalmic Physiol Opt 34: 489-497.

12. Bergeron CM, Wanet-Defalque MC (2013) Psychological adaptation to visual impairment: The traditional grief process revised. Br J Vis Impair 31: 20-31.

Copyright: (C2018 Gangos CJ. This is an open-access article distributed under the terms of the Creative Commons Attribution License, which permits unrestricted use, distribution, and reproduction in any medium, provided the original author and source are credited. 